Analysis of antibiotic resistance patterns by strain

\begin{tabular}{lc} 
Resistance phenotype & No of strains \\
\hline Trimethoprim & 21 \\
Erythromycin & 28 \\
Tetracycline, doxycycline & 40 \\
Erythromycin, clindamycin & 64 \\
Trimethoprim, erythromycin & 5 \\
Tetracycline, doxycycline, erythromycin & 4 \\
Tetracycline, doxycycline, erythromycin, clindamycin & 7 \\
Trimethoprim, erythromycin, clindamycin & 2 \\
\hline Total & 171 \\
\hline
\end{tabular}

\section{Comment}

In 1976 Leyden reported the complete absence of antibiotic resistant propionibacteria in over 1000 patients with acne. ${ }^{2}$ The high prevalence of resistance in our study highlights the need for policies to restrict the use of antibiotics to limit the spread of resistant strains and hence preserve the effectiveness of antibiotics in treating acne. There are 23 ways of prescribing antibiotics for acne based on oral, topical, or combined use of available preparations. The relative risk of developing resistance with each regimen is unknown. Minocycline is the only antiacne antibiotic to which cutaneous propionibacteria have not acquired resistance, although it is widely prescribed. Patients who respond to antibiotics do not harbour propionibacteria resistant to the therapeutic drug, except for a few of those treated with topical erythromycin.

We recommend the following guidelines for anti- biotic treatment of acne in both hospital and general practice. Firstly, do not prescribe antibiotics if a nonantibiotic topical preparation will suffice. Secondly, continue treatment for no longer than is necessary (accepting that six months is the minimum). Thirdly, if further treatment is required reuse the same drug whenever possible. Short intervening courses of topical treatment with an antibacterial agent such as benzoyl peroxide may help to eliminate any resistant propionibacteria that have been selected. Finally, avoid concomitant oral and topical treatment with chemically dissimilar antibiotics to reduce the risk of resistance developing to both. The concept of long term rotational antibiotics for acne is outdated and this practice should be avoided. Patients must not expect an endless supply of alternative drugs.

General practitioners and dermatologists should now consider propionibacterial resistance as a cause of therapeutic failure. Whenever possible, patients who do not respond to antibiotics should be screened for resistant strains. A protocol based on the methods used in this study may be obtained from us.

\section{Cunliffe WJ. Acne. London: Martin Dunitz. 1989}

2 Leyden JJ. Antibiotic resistant acne Cutis 1976;17:593-6.

3 Crawford WW, Crawford IP, Stoughton RB, Cornell RC. Laboratory induction and clinical occurrence of combined clindamycin and erythromycin resistance in Corynebacterium acnes. I Invest Dermatol 1978;72:187-90.

4 Leyden JJ, McGinley KJ, Cavalieri S, Webster GF, Mills OH, Kligman AM. Propionibacterium acnes resistance to antibiotics in acne patients. $\mathcal{F}$ Am Acad Dermatol 1983;8:41-5.

5 Eady EA, Cove JH, Holland KT, Cunliffe WJ. Erythromycin resistan propionibacteria in antibiotic treated acne patients: association with therapeutic failure. Br $\mathcal{J}$ Dermatol 1989;121:51-7.

(Accepted 16 December 1992)

\title{
Knowledge and use of secondary contraception among patients requesting termination of pregnancy
}

\section{R Bromham, R S V Cartmill}

Fertility Control Unit, St James's University Hospital, Leeds LS9 7TF D R Bromham, senior lecturer in obstetrics and gynaecology R S V Cartmill, research registrar

Correspondence to: $\mathrm{Mr}$ Bromham.

$B M \mathcal{F} 1993 ; 306: 556-7$
Studies of the contraception used before an unplanned pregnancy indicate that an increasing proportion of such pregnancies are due to condom failure..$^{1-3}$ It is vital that people know of secondary methods of contraception, and we investigate here the current extent of this knowledge.

\section{Patients, methods, and results}

We interviewed 769 of the 808 patients attending our clinic between 1 April 1991 and 31 January 1992 for whom termination of pregnancy was agreed under the Abortion Act; those interviewed included $62(8 \%)$ Afro-Caribbean and 69 (9\%) Asian patients. The simple structured interview covered patients' knowledge and previous use of contraceptives and knowledge of secondary methods of contraception to be used if failure of a primary method was suspected. The source of advice on family planning was also recorded.

In 307 cases the method used at conception was known to be less effective than one previously used by the same patient. This usually represented a change from the combined pill to condoms. A potential failure of contraception had been recognised by 171 patients: 93 reported a split or leaking condom; 13 reported a condom coming off during intercourse; 32 admitted inconsistent use of condoms; 32 reported forgetting to take contraceptive pills or taking antibiotics concurrently with the pill; and one reported a late injection of medroxyprogesterone acetate. The 138 patients who had recognised a potential condom failure represented only $45 \%$ of the 309 who had conceived while using this method. Only 20 of them had attempted to use a secondary or emergency contraceptive method; this was the postcoital pill in all cases.

An adequate knowledge of the existence, timing, and source of postcoital pills was shown by $52(30 \%)$ of the 171 patients who had recognised a potential contraceptive failure and $25(12 \%)$ of the 210 who had not used any contraception - that is, $77(20 \%)$ of the 381 patients who might have benefited from their use Knowledge of postcoital insertion of an intrauterine contraceptive device was shown by four $(2 \%)$ of the 171 and two (1\%) of the 210 respectively - that is, only six (2\%) of the 381 who might have benefited. Most patients $(718 / 769)$ would have preferred to use postcoital contraception than experience an unplanned pregnancy. Of the patients surveyed, 501 had received advice on contraceptives from a general practitioner and 102 from a community family planning clinic, and 163 had not received medical advice (no information was available from three patients). Among those who had received medical advice, knowledge of postcoital contraceptive methods differed significantly according to the source of that advice (table).

Number (percentage) of patients accepted for termination of pregnancy who had received advice on contraception from general practitioners $(n=501)$ or family planning clinics $(n=102)$ and knew of postcoital contraceptive methods

\begin{tabular}{lccc}
\hline & \multicolumn{2}{c}{ Source of contraceptive advice } & \\
\cline { 2 - 3 } Contraceptive method & $\begin{array}{c}\text { General } \\
\text { practitioner }\end{array}$ & $\begin{array}{c}\text { Family planning } \\
\text { clinic }\end{array}$ & p Value* \\
\hline Postcoital pill: & & & \\
Knew it exists & $354(71)$ & $82(80)$ & $<0.05$ \\
Knew when to use it & $104(21)$ & $33(32)$ & $<0.05$ \\
Knew where to get it & $251(50)$ & $61(60)$ & NS \\
Knew all three above & $99(20)$ & $33(32)$ & $<0.01$ \\
Postcoital intrauterine device: & $54(11)$ & $16(16)$ & NS \\
Knew it exists & $10(2)$ & $4(4)$ & NS \\
Knew when to use it & $7(1)$ & $3(3)$ & NS \\
Knew both of above & $7(1)$ & & \\
\hline
\end{tabular}

$\star \chi^{2}$ test with Yates's correction. 
We asked 422 patients who had used the combined pill at some time about their knowledge of appropriate secondary methods of contraception to be used in the event of forgotten pills, severe vomiting, severe diarrhoea, and concurrent antibiotic treatment. Four correct replies were given by $70(19 \%)$ of the 372 patients instructed by general practitioners and 25 $(50 \%)$ of the 50 instructed in community family planning clinics. This difference was significant $(p<0.001)$ and was not explained by age, parity, marital status, or social class, which were similar in both groups.

\section{Comment}

Self selection bias-for example, because of better informed and motivated patients seeking advice from specialist clinics-cannot be excluded from this study. Our results are, however, consistent with those of previous studies which suggest that patients attending

\section{Weak link in vaccine cold chain}

\section{Hilary Briggs, Susan Ilett}

University of Birmingham, Birmingham B15 2TT Hilary Briggs, medical student

Centre for Community Health, St Patrick's, Birmingham B12 0YA Susan Ilett, consultant community paediatrician

Correspondence to: Dr Ilett.

BMF 1993;306:557-8
The efficacy of vaccines, especially live vaccines, may be compromised unless they are kept at $2-8^{\circ} \mathrm{C}$ (or $0-4^{\circ} \mathrm{C}$ for polio vaccine) at every stage of the cold chain from manufacturer to recipient. In tropical countries the importance of maintaining the cold chain is recognised, but in temperate countries it has been given little attention until recently. Results from Hungary indicated that vaccines were exposed to heat during transport and that facilities for refrigeration were inadequte,' and recent British studies have shown that the storage of vaccines is inadequate in general practices and health authority premises. ${ }^{23} \mathrm{We}$ assessed the conditions in which vaccines were transported in Birmingham during the summer and surveyed the modes of transport used.

\section{Methods and results}

Vaccines were transported from a central distribution point to 53 general practices and six health clinics in the former Central Birmingham Health District. Staff from the general practices collected their vaccines from the central office, while health clinics received theirs from the district's transport service. Each of the 138 orders for vaccines studied was made up into an ordinary envelope that contained a Monitor Mark Time-Temperature Integrator Tag $(3-M)$. This is a laminated strip that, once activated, indicates exposure to temperatures over $10^{\circ} \mathrm{C}$ by the progression of a blue dye along the strip. It is accurate to within $1^{\circ} \mathrm{C}$ of the

Number (percentage) of packages of vaccines exposed to excessive temperatures during transport from central distribution point $(n=104)$

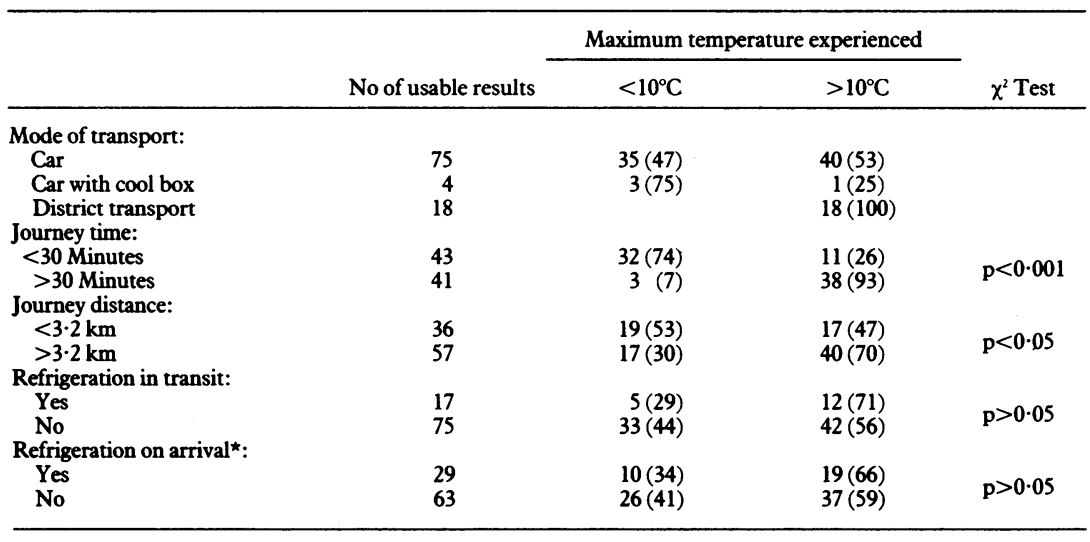

$\star$ Refrigeration between arrival and opening of package. general practitioners (the main source of contraceptive advice) are less knowledgeable than those attending specialist clinics. ${ }^{14}$ An audit of unplanned pregnancies seen in one practice also emphasised the need for great care in counselling people using the pill. ${ }^{3}$ Efforts to encourage the use of condoms as protection against sexually transmitted infections should emphasise their use as well as rather than instead of more effective contraceptive methods, but greater knowledge of postcoital methods and their use is also vital. ${ }^{\text {s }}$

1 Duncan G, Harper C, Ashwell E, Mant D, Buchan H, Jones L. Termination of pregnancy: lessons for prevention. British Jourmal of Family Planning 1990;15:112-7.

2 Griffiths $M$. Contraceptive practices and contraceptive failure among women requesting termination of pregnancy. British fournal of Family Planning requesting termin $1990 ; 16-8$.

3 Melville AWT, McElduff J. Termination of pregnancy in a general practice. Medical Audit News 1992;2:130-1.

4 Brook SJ, Smith C. Do combined oral contraceptive users know how to take their pill properly? British fournal of Family Planning 1991;17:18-20.

5 National Association of Family Planning Doctors. Emergency (postcoital) contraception guidelines for doctors. London: NAFPD, 1992.

(Accepted 7 fanuary 1993)

actual temperature in the package (information supplied by manufacturer). Thus any breakdown in the cold chain could be quantified.

Data on exposure to high temperatures and on transport (such as mode, duration, distance, and refrigeration) were obtained by means of a short questionnaire completed by the recipient on opening the package of vaccine. The ambient temperature for each day of the study was determined from local weekly weather statistics.

Altogether 104 questionnaires were usable. The table shows the results; some results were excluded because information was lacking or, in three cases, the spread of blue dye along the indicator strip was extensive and clearly inconsistent with other details. Sixty six of the vaccine packages had been exposed to temperatures $>10^{\circ} \mathrm{C}$. All vaccines transported by the district transport service, which does not use refrigerators and is not provided with cool boxes, were exposed to excessive temperatures. Over half of those transported by car were similarly exposed. The proportion of vaccines exposed to $>10^{\circ} \mathrm{C}$ was significantly higher when the journeys lasted more than 30 minutes or were greater than $3.2 \mathrm{~km}$. Temporary refrigeration of vaccines during or after their transport had no benefit and may be falsely reassuring. The mean maximum daily temperature during the study was 21 (range $11-27)^{\circ} \mathrm{C}$. The daily temperatures were not related to exposure of the vaccines to temperatures $>10^{\circ} \mathrm{C}$.

\section{Comment}

The only successful means of transporting vaccines without excessive warming was by car, and this depended on speed of transit. The use of cool boxes was so rare that we cannot comment on their potential effectiveness, and it is difficult to obtain small cool boxes of known effectiveness in Britain.

We welcome the Department of Health's takeover of the distribution of vaccines. ${ }^{4}$ This will not, however, address the deficiencies of local storage facilities on those occasions, such as immunisation of children at school, when vaccines need to be transported to other sites. The World Health Organisation recommends that all polio vaccines that are exposed to temperatures over $10^{\circ} \mathrm{C}$ for more than a day (five days for measles vaccines) should be used within three months. Thus the cumulative effect of inadequate transport, poor storage, and exposure in consulting rooms during clinics may be considerable. Using cool boxes of known effectiveness, improved staff training, and random monitoring exercises similar to this one would improve a potentially hazardous situation. 